\title{
Violência contra o idoso: uma análise documental preliminar de denúncias no município de Natal, Rio Grande do Norte
}

\author{
Rodrigo da Silva Maia*, Camomila Lira Ferreira**, Eulália Maria Chaves Maia***
}

\section{Resumo}

O número de idosos está crescendo em uma escala sem precedentes na história da humanidade. Dentro desse contexto, a violência perpetrada contra o idoso começa a ganhar visibilidade. Este estudo está sendo realizado no município de Natal, Rio Grande do Norte, e objetiva descrever as denúncias de violência praticada contra essa população com base na análise dos documentos do Programa SOS Idoso, os dados parciais são referentes aos anos 2004 e 2005. Esta pesquisa é de caráter transversal, descritivo, retrospectivo e documental. Entre os resultados mais relevantes, tem-se que uma parcela dos idosos que sofrem agressão é do sexo feminino e que a violência, em sua maioria, é perpetrada por familiares. Por se tratar de dados parciais, as informações apresentadas não permitem afirmações conclusivas. Todavia, os achados ajudam a perceber a gravidade do problema e para orientar as proposições de ações assistenciais no âmbito de políticas públicas de saúde e sociais que visem prevenção e proteção integral ao idoso.

Palavras-chave: Idoso. Envelhecimento. Denúncia. Violência doméstica.

\section{Introdução}

Envelhecer é um processo evolutivo natural que faz parte do desenvolvimento humano. Os jovens de hoje, no futuro, farão parte da população de idosos, que cresce em uma escala sem precedentes na história da humanidade. $\mathrm{O}$ aumento da população de idosos, pessoas de 60 anos ou mais, está acontecendo em todo o

* Doutorando no Programa de Pós-Graduação em Psicologia da Universidade Federal do Rio Grande do Norte. Mestre e graduado em Psicologia pela Universidade Federal do Rio Grande do Norte. Docente do Centro Universitário Facex. Endereço para correspondência: Rua Engenheiro Nelson Mattos, 1839, Nova Descoberta, Natal, RN, Brasil. CEP 59075-380. E-mail: rodrigo_maia89@yahoo.com.br

** Mestre pelo Programa de Pós-Graduação em Ciências da Saúde da Universidade Federal do Rio Grande do Norte. Graduada em Psicologia pela Universidade Federal do Rio Grande do Norte. Servidora da Secretaria Estadual de Saúde do Estado do Rio Grande do Norte, Natal, RN. Brasil. E-mail: camomilapsi@yahoo.com.br

**** Doutora pelo Programa de Pós-Graduação em Psicologia Clínica do Instituto de Psicologia da Universidade de São Paulo. Professora titular do Departamento de Psicologia da Universidade Federal do Rio Grande do Norte. Orientadora dos Programas de Pós-Graduação em Ciências da Saúde e em Psicologia da Universidade Federal do Rio Grande do Norte, Natal, RN, Brasil. E-mail: eulalia.maia@yahoo.com.br

$\rightarrow$ http://dx.doi.org/10.5335/rbceh.v13i2.5763

Recebido em: 27/02/2016. Aceito em: 10/08/2016. 
mundo de modo exponencial. Nos países desenvolvidos, acontece de forma lenta e gradual, o que permite a melhor estruturação dos serviços especializados em saúde e outras formas de assistência ao idoso (ORGANIZAÇÃO MUNDIAL DA SAÚDE, 2005).

Em contrapartida, nos países em desenvolvimento, esse processo ocorre em uma proporção muito rápida para os recursos e avanços disponíveis nesse campo. Isso produz um fenômeno paradoxal, pois se, por um lado, o envelhecimento populacional é visto como uma grande conquista da humanidade devido aos avanços tecnológicos, maior acesso aos serviços sociossanitários, queda de fecundidade, aumento da expectativa de vida, redução da mortalidade, entre outros fatores, por outro, é visto como um problema, um desafio, com enormes demandas para a sociedade, tais como a aposentadoria, a epidemia de doenças crônicas com suas sequelas e complicações, a carência de criação de mais serviços sociais e de saúde que realmente atendam às particularidades dessa faixa etária, a necessidade de cuidados de longa duração, etc. (MINAYO, 2003).

Associada ao crescente envelhecimento da população, existe a necessidade de garantir oportunidades de acesso à saúde e à segurança de modo continuado ao longo da vida. Logo, torna-se emergente o desenvolvimento de políticas públicas voltadas à atenção integral ao idoso, baseadas em direitos, necessidades, interesses e habilidades das pessoas mais velhas (ORGANIZAÇÃO MUNDIAL DA SAÚDE, 2005). Essas políticas devem assisti-las no âmbito da justiça, seguridade social, previdência, saúde, educação e quanto a todos os outros direitos fundamentais prezados pela Constituição federal de 1988, o que, por sua vez, promove a garantia aos direitos da pessoa idosa (VERAS, 2009). No entanto, sabe-se que a atenção integral à pessoa idosa, visando ao seu desenvolvimento e às condições de existência plenas, não está sendo garantida, especialmente, quando se observa a ocorrência de situações de maus-tratos e de violência contra essa população.

Esse fenômeno cresce mundialmente, permeando, de modo expressivo, as relações interpessoais e intergrupais. Trata-se de uma questão recorrentemente vivenciada na realidade do nosso país, sendo comumente caracterizada sob o estereótipo de desvio de conduta e materializada na figura da criminalidade e dos maus-tratos (OLIVEIRA, 2008).

É notória a imensa quantidade de indivíduos - crianças, adolescentes, jovens, adultos, homens, mulheres ou idosos - que são vítimas de violência, negligência, maus-tratos ou discriminação. Com frequência e gravidade que aumenta exponencialmente, esse fenômeno permeia os espaços de convivência social, acontece no âmbito familiar, domiciliar ou em instituições assistenciais e os direitos e a cidadania de quem passa por essa situação são cruelmente desrespeitados (FALEIROS, 2004; GAIOLI; RODRIGUES, 2008).

A violência é um fenômeno socialmente construído, subjetivo e deflagrador das contradições sociais, caracterizando-se 
como multidimensional e multifacetado, que necessita ser conceituado e compreendido em sua expressão e em seus impactos sobre quem a sofre. Nesse sentido, nas últimas décadas, começou a ganhar visibilidade a violência perpetrada contra o idoso. Sua notificação é recente no Brasil e no mundo. Apenas em 1975 é que os abusos ganharam repercussão nas revistas científicas britânicas, como o espancamento de avós. Já no Brasil, somente em 1990 essa questão passou a ser discutida e observada (BRASIL, 2005). Em 2003, com o Estatuto do Idoso (BRASIL, 2004), tornou-se obrigatória a notificação de maus-tratos contra indivíduos dessa faixa etária. $\mathrm{O}$ artigo 19 desse documento estabelece que é obrigatório denunciar aos órgãos competentes casos de suspeita ou confirmação de maus-tratos contra o idoso.

A Organização Mundial de Saúde (OMS) (2014) define violência como sendo o ato ou a omissão, voluntária ou não, que eventualmente cause dano ao indivíduo, nesse caso, a pessoa idosa. $\mathrm{O}$ mesmo órgão propõe uma classificação, que é amplamente utilizada pelos serviços de atenção à pessoa idosa (CORREIA et al., 2012), que estabelece que a violência contra a pessoa idosa pode ser classificada como violência física, psicológica ou emocional - que inclui as violências verbal, sexual, econômica ou financeira, negligência e autonegligência. Destaca-se que a definição da OMS aponta que o abuso resulta em sofrimento, dor ou lesão, perda ou violação desnecessária e que, consequentemente, acarretará em

RBCEH, Passo Fundo, v. 13, n. 2, p. I13-123, maio/ago. 2016 prejuízo da qualidade de vida do idoso (OMS, 2002).

A violência contra o idoso, portanto, é considerado um problema delicado, uma vez que não envolve somente o idoso vítima da violência. $\mathrm{O}$ fenômeno envolve, também, sua família, os profissionais que dele cuidam e todo o sistema de proteção/garantia dos direitos da pessoa idosa (MINAYO, 2003).

Apesar de a discussão sobre a violência estar em ascensão e ganhar visibilidade social e na mídia, ainda há dificuldade para se rastrear os casos, identificar e prevenir a ocorrência do fenômeno. Dentre os motivos que impedem a difusão da informação e dificultam a denúncia, elencados como os principais agentes que geram a subnotificação da violência, destacam-se o grau de proximidade e/ ou parentesco do agressor com a vítima ou as situações de dependência afetivo-emocional, de cuidado ou financeira que existem na relação vítima-agressor, por exemplo (GAIOLI; RODRIGUES, 2008; SANCHES; LEBRÃO; DUARTE, 2008; SALES et al., 2014).

Buscando dar visibilidade ao fenômeno e contribuir para a prevenção e o combate à violência contra o idoso, em Natal, RN, funcionava o programa SOS Idoso, vinculado à Secretaria Municipal de Trabalho e Assistência Social do município. Criado no ano de 2003, o programa tinha o objetivo de receber e averiguar denúncias relacionadas às situações de violação dos direitos do idoso, em especial, situações de violência, buscando proteger e assegurar os direitos fundamentais, a qualidade de vida 
e o bem-estar do idoso vitimado. Esse programa agora é chamado Serviço de Convivência e Fortalecimento de Vínculos, tendo sido ampliado para atender demandas psicossociais de violência contra crianças, adolescentes, mulheres, negros, idosos, dentre outros.

Diante da relevância desse fenômeno na realidade brasileira, da notória subnotificação e da necessidade de dar visibilidade social a um fenômeno em ascensão, objetiva-se neste artigo descrever o fenômeno da violência contra a pessoa idosa no município de Natal, $\mathrm{RN}$, com base na análise de documentos primários do Programa SOS Idoso, em especial, apresentando dados preliminares dos anos 2004 a 2005.

\section{Materiais e método}

Esta pesquisa é de caráter transversal, descritivo, retrospectivo e documental. Os dados foram coletados após análise minuciosa dos registros de ocorrência entre os anos 2004 e 2009 do serviço do SOS Idoso, disponibilizados para a presente pesquisa. O trabalho de coleta de dados contemplou as denúncias dos anos 2004 e 2005. Portanto, trata-se de uma pesquisa em andamento da qual serão apresentados os dados parciais.

$\mathrm{O}$ registro das informações exigiu a leitura integral de todos os casos, seguida da categorização dos dados, realizada por avaliadores, os três autores do artigo. Ainda assim, algumas variáveis não puderam ser controladas e se perderam por insuficiência de informações no preenchimento das denúncias. Ressalta-se que os dados que poderiam identificar o denunciante foram omitidos a fim de garantir o sigilo, a privacidade e a confidencialidade dos dados.

Após serem coletados e categorizados, os dados foram organizados com o auxílio do programa Statistical Package for the Social Sciences - versão 20.0. Para o tratamento das variáveis, utilizou-se a análise descritiva, em especial a análise de frequência e obtenção das medidas de tendência central e de dispersão.

Para a coleta das informações, foi solicitada a anuência da coordenação do programa, que autorizou o acesso e uso dos dados por meio de documento de concessão das informações e do consentimento livre e esclarecido assinado pelos representantes da gestão do serviço. A pesquisa foi aprovada pelo Comitê de Ética em Pesquisas da Universidade Federal do Rio Grande do Norte, sob Protocolo $n^{\circ}$ 022/2006. O presente estudo seguiu os preceitos éticos de confidencialidade, sigilo e privacidade dos dados, visando garantir o anonimato e a seguridade aos denunciantes, alicerçado na Resolução no 466/2012, do Conselho Nacional de Saúde.

\section{Análise e discussão dos dados}

Foram registradas 2.397 denúncias entre os anos 2004 e 2009. No que se refere aos anos 2004 e 2005, a amostra foi composta de 315 denúncias de idosos, sendo $66,3 \%(\mathrm{n}=209)$ realizadas por idosos do sexo feminino. A faixa etária predominante foi de 80 anos ou mais $(36,5 \%, \mathrm{n}=115)$, seguida de idades dos 
75 aos 79 anos $(21,9 \%, \mathrm{n}=69)$, com um maior número de idosos $(27,9 \%, \mathrm{n}=88)$ residentes em um distrito administrativo de alto índice de vulnerabilidade social. Quanto à violência sofrida, a maioria foi de violências múltiplas $(28,9 \%, \mathrm{n}=91)$, agressão verbal $(14,6 \%, \mathrm{n}=46)$, agressão psicológica $(11,7 \%, \mathrm{n}=37)$ e abandono $(10,5 \%, n=33)$, totalizando $65,7 \%(n=207)$ das denúncias. Os demais dados podem ser visualizados na Tabela 1.

Tabela 1 - Dados da população de idosos violentados

\begin{tabular}{|c|c|c|}
\hline \multicolumn{2}{|c|}{ Dados e variáveis } & $\%(F A)$ \\
\hline \multirow{2}{*}{ Sexo } & Masculino & $33,6(106)$ \\
\hline & Feminino & $66,3(209)$ \\
\hline \multirow{4}{*}{$\begin{array}{l}\text { Distrito de } \\
\text { domicílio }\end{array}$} & Norte & $24,8(78)$ \\
\hline & Sul & $23,2(73)$ \\
\hline & Leste & $24,1(76)$ \\
\hline & Oeste & $27,9(88)$ \\
\hline \multirow{5}{*}{$\begin{array}{l}\text { Tipo de } \\
\text { violência }\end{array}$} & $\begin{array}{l}\text { Violências múltiplas } \\
\text { (duas ou mais violências) }\end{array}$ & $28,9(91)$ \\
\hline & Agressão verbal & $14,6(46)$ \\
\hline & Agressão psicológica & $11,7(37)$ \\
\hline & Abandono & $10,5(33)$ \\
\hline & $\begin{array}{l}\text { Informações não } \\
\text { esclarecidas sobre a } \\
\text { violência sofrida }\end{array}$ & $34,3(108)$ \\
\hline
\end{tabular}

Fonte: primária.

Nota: \% - porcentagem; FA - frequência absoluta.

O agressor, comumente, é do sexo feminino $(43,8 \%, \mathrm{n}=138)$, seguido do masculino, com $39,7 \%(\mathrm{n}=125)$, sendo $16,5 \%$ dos casos com informações não declaradas. A maioria dos agressores foram os filhos $(49,8 \%, \mathrm{n}=157)$, seguido de netos $(10,5 \%, \mathrm{n}=33)$ e outros indivíduos sem parentesco $(10,2 \%, n=32)$. A idade média dos agressores foi de 41 anos ( $\mathrm{DP}=21)$, havendo a presença de violadores com idade mínima de 6 anos e máxima de 86 anos. Identificou-se, ainda, que $13,3 \%(n=42)$ dos agressores faziam uso de alguma substância psicotrópica. Na Tabela 2, constam algumas informações resumidas.

Tabela 2 - Dados da população de agressores

\begin{tabular}{l|l|r}
\hline \multicolumn{2}{c|}{ Dados e variáveis } & \multicolumn{1}{c}{$\%($ FA) } \\
\hline \multirow{3}{*}{ Sexo } & Masculino & $39,7(125)$ \\
& Feminino & $43,8(138)$ \\
& $\begin{array}{l}\text { Informações não } \\
\text { esclarecidas }\end{array}$ & $16,5(52)$ \\
\hline \multirow{2}{*}{$\begin{array}{l}\text { Parentesco } \\
\text { do agressor }\end{array}$} & Filhos & $49,8(157)$ \\
& Netos & $10,5(33)$ \\
\hline Usdivíduos sem & $10,2(32)$ \\
substância & parentesco & $29,5(93)$ \\
\hline
\end{tabular}

Fonte: primária.

Nota: \% - porcentagem; FA - frequência absoluta.

Nos registros de denúncia, o sexo feminino foi preponderante, o que corrobora outros estudos (MELO; CUNHA; FALBO NETO, 2006; MAIA; MAIA, 2015). Em um estudo de revisão de literatura, Minayo (2003) afirma que as mulheres, via de regra, sofrem mais com a violência intrafamiliar e que a violência urbana ocorre mais frequentemente com os homens. Outros estudos levantam a questão dos fatores de risco e colocam a mulher como mais vulnerável em todas as faixas etárias. Assim, a violência pode ser mais suscetível quando a mulher sofre violência doméstica antes de enve- 
lhecer e, na velhice, esse quadro tende a manter-se ou a agravar-se (GALVÃO; ANDRADE, 2004).

No que concerne à faixa de idade, os idosos acima de 75 anos foram os que mais denunciaram no serviço. Embora o envelhecimento não esteja, necessariamente, atrelado a doenças e incapacidades, as doenças crônico-degenerativas são frequentemente constatadas em idosos. Assim, à medida que aumenta 0 número de idosos que vivem mais, consequentemente, também cresce a quantidade de indivíduos nessa faixa etária que apresentam doenças crônicas. Esse aumento no número de doenças crônicas está diretamente relacionado à maior incapacidade funcional. Nesse sentido, o comprometimento da capacidade funcional do idoso traz para a família implicações importantes, uma vez que gera dependência e perda de autonomia do idoso, o que exige um maior cuidado (ALVES et al., 2007). A doença do idoso, portanto, e a consequente diminuição de sua capacidade funcional e cognitiva são importantes fatores de risco que colaboram com a violência. Hazzard e colaboradores (2003) afirmam que é significativo o efeito da idade avançada atrelado a outros fatores que culminam em incapacidades e consequentes perdas de autonomia, tais como: demência, fraturas de quadril, acidentes vasculares cerebrais, doenças reumatológicas e deficiências visuais.

Quanto à violência sofrida, a maioria foi de violências múltiplas $(28,9 \%, \mathrm{n}=91)$, que é quando se identifica que o idoso sofre mais de um tipo de violência, que envolve, geralmente, agressão psicológica, agressão verbal, agressão física e negligência associadas. No Brasil, Souza e colaboradores (2008) observaram que os motivos mais comuns de denúncias na Delegacia do Idoso são os maus-tratos (48,5\%), o constrangimento ilegal $(11,1 \%)$, a apropriação indébita $(10 \%)$ e a ameaça $(9,4 \%)$. Já no Núcleo Especial de Atendimento à Pessoa Idosa foram constatados os maus-tratos $(47,4 \%)$ e a apropriação indébita $(24,0 \%)$ como queixas mais recorrentes dos idosos. Nesse último órgão, surge o abandono com maior frequência nas denúncias, sendo $21 \%$ dos registros realizados no ano de 2004.

Vale salientar que o abuso financeiro, que aparecia anteriormente relacionado às famílias de muitas posses, muda sua configuração e alcança, cada vez mais, a população de baixa renda, acarretando danos cumulativos nos idosos, visto que se sentem impotentes diante da situação. Desse modo, outras questões podem surgir, culminando em uma avalanche de perdas: financeiras, psíquicas e até físicas, muitas vezes irreversíveis. É comum haver pessoas que se apresentam para ajudar o idoso, mas lhe subtraem o benefício. Em outros casos, os próprios familiares o obrigam ou induzem a realizar empréstimos consignados que, muitas vezes, não condizem com a renda do contratado (SANCHES, LEBRÃO, DUARTE, 2008).

No tocante ao agressor, as mulheres ganham destaque. Entre os vários fatores que podem contribuir para essa atitude está o fato de que é elas que se tornam as grandes cuidadoras de idosos 
incapacitados. Esse fenômeno pode ser compreendido no Brasil como uma questão cultural já que a sociedade espera e cobra da mulher esse papel (NERI, 1993).

Os filhos aparecem como os que mais agridem, esse dado também foi encontrado em outros estudos realizados no Brasil e no mundo (MINAYO, 2003; FALEIROS, 2007; PLONER, HOFFMANN, BALDISSERA, 2014). Entre os diversos fatores que podem ter relação com esse fato, há o aparecimento de quadros incapacitantes ou perda do cônjuge, o que obriga alguns idosos a ter de residir com outros parentes, que, inseridos em uma rotina própria, podem não dispor de tempo para o idoso, ainda mais quando ele é dependente. Somado a isso, o espaço físico pode não comportar mais uma pessoa, o que, possivelmente, pode ser fonte de conflitos familiares. Também, entre os agressores surgiu a variável uso de álcool e drogas, como se percebe anteriormente, esse é um fator de risco para a ocorrência de violência, como mencionado por Minayo (2003).

Diante do exposto, as questões familiares precisam ser colocadas em pauta. A família é um importante instrumento de sustentação e pertencimento para o idoso. Quando ela não apresenta condições de prestar assistência, o idoso fica exposto a uma série de riscos, tanto físicos como psíquicos ou sociais. No Brasil, em decorrência da enorme exclusão social, o idoso e sua família podem ser vistos como mais um segmento à margem da sociedade, em especial o dependente, pobre e sem recursos, tanto no âmbito da saúde como no das políticas sociais (MAZZA; LEFEVRE, 2005).

Nesse sentido, a presença do cuidador está intimamente relacionada a essas questões (MAIA et al., 2010), pois é no espaço doméstico que o idoso vive e necessita de ajuda para realizar suas atividades cotidianas, com o objetivo da preservação de sua autonomia e de sua independência (MAZZA; LEFEVRE, 2005).

Em grande parte dos casos, o cuidado é exercido pelos cônjuges e pelos filhos, especificamente as filhas, geralmente, na faixa etária de 45 a 50 anos, sendo solteiras, casadas ou viúvas e, geralmente, já aposentadas. Além disso, é comum que toda carga de cuidado seja depositada sob a responsabilidade de um único cuidador, o que o sobrecarrega e eleva seu nível de estresse, sendo esse, também, um potencial fator de risco para a ocorrência da violência (MAZZA; LEFEVRE, 2005).

Todos esses fatores são interessantes para a melhor compreensão dos dados relatados, já que é no ambiente familiar que ocorrem os maiores índices de violência contra o idoso, o que nos leva a crer que os vínculos familiares precisam ser problematizados, com o intuito de prevenir a ocorrência de situações de violência contra idosos.

Minayo (2003) realizou uma revisão na literatura nacional e internacional para investigar, entre outras aspectos, fatores de risco que estão associados à violência contra o idoso. Destaca-se então o fato de agressor e vítima residirem na mesma casa, os filhos serem dependentes financeiramente de seus pais 
de idade avançada, todo o provimento do idoso depender da família para sua manutenção e sobrevivência, o abuso de álcool e drogas pelos filhos, por outros adultos da casa ou pelo próprio idoso; existir, na família, vínculos afetivos e comunicativos frágeis, isolamento social dos familiares e/ou da pessoa de idade avançada, o fato de o idoso ter sido ou ser uma pessoa agressiva nas relações com seus familiares, haver histórico de violência na família, os cuidadores terem sido vítimas de violência doméstica ou padecerem de transtornos psiquiátricos. Em resumo, a realidade encontrada nessa revisão parece repetir-se no perfil encontrado na presente pesquisa.

Ressalta-se que esses dados podem não condizer com a realidade, uma vez que ocorre o fenômeno da subnotificação, que ocorre pelas dificuldades que estão ligadas tanto à denúncia quanto à detecção da violência, bem como por questões problemáticas nos serviços que acolhem e recebem as denúncias (GAIOLI; RODRIGUES, 2008; SANCHES; LEBRÃO; DUARTE, 2008; SALES et al., 2014). Faleiros (2007) afirma que alguns idosos não denunciam os agressores porque, na maioria dos casos, são familiares. Ele utiliza o termo "segredo" ou "conluio familiar", o que faz com que os idosos violentados não façam a denúncia.

Maia e colaboradores (2010), em uma revisão de literatura, também encontraram a família como principal agressora e o silêncio do idoso como um fator que corrobora para a subnotificação dos casos. Tal fato torna-se compreensível, uma vez que deve ser bastante angustiante para o idoso ter de denunciar alguém com quem, provavelmente, conviveu boa parte de sua vida e por quem, possivelmente, alimenta sentimentos de afeto. Somado a isso, punir com reclusão esse familiar pode significar afastar a única pessoa com quem ele pode contar. Outro fator que pode estar implicado é o medo de sofrer represálias.

\section{Considerações finais}

A violência contra o idoso faz parte de uma questão recente. No SOS Idoso, programa da cidade de Natal, o número de denúncias aumenta a cada ano, embora, nos dois anos cujos dados são apresentados neste trabalho, as notificações ainda eram muito incipientes e muitos dados tenham sido perdidos. Atualmente, todos os registros são armazenados digitalmente, mas ainda que se tenha tomado medidas mais eficazes para o gerenciamento das informações, vale lembrar que existe uma elevada subnotificação da violência perpetrada, não apenas no Brasil, como em todo o mundo. Sendo assim, pode-se dizer que os dados apresentados não permitem afirmações conclusivas. Todavia, ajudam a perceber a gravidade do problema e servem para orientar as proposições de ações assistenciais no âmbito de políticas públicas de saúde e sociais que visem prevenção e proteção integral ao idoso.

Em meio a tudo que foi apresentado, é de suma relevância a elaboração de ações mais eficazes e oportunas para que os idosos vivenciem essa etapa do desenvolvimento, desfrutando de uma 
qualidade de vida satisfatória para seu bem-estar biopsicossocial. Para que isso se torne realidade, é preciso que todos os setores sociais participem desse propósito e que os serviços se estruturem de modo a acolher de forma plena essa problemática. A começar pela conscientização da família e da sociedade quanto à necessidade de mudança no modo de lidar com a questão do envelhecimento. Oportunizar aos idosos meios de desenvolver um envelhecimento saudável, pleno e bem sucedido, implementando e ampliando a rede de cobertura dos serviços e programas de atenção a essa faixa etária, é quebrar paradigmas e avançar em novas práticas e novos conceitos sobre envelhecer que realmente correspondam às reais necessidades dos idosos.

\section{Violence against the elderly: a preliminary documental analisys of complaints in the city of Natal, Rio Grande do Norte}

\section{Abstract}

The number of elderly has grown on an unprecedented scale in human history. Within this context, the violence perpetrated against the elderly is beginning to gain visibility. This study is being conducted in the city of Natal and aims to describe the complaints of violence against this population from the analysis of the documents allocated in SOS elderly program with partial data for the years of 2004 and 2005. This study are transversal, descriptive, retrospective and documentary. Among the most relevant results we have a portion of elderly people who suffer are female aggression and violence, mostly perpetrated by family members. Because these are partial data we can say that the data presented here do not allow conclusive statements. Therefore, the findings help to understand the severity of the problem and serve to guide the propositions of care actions in public health and social policies aiming at prevention and comprehensive protection for the elderly.

Keywords: Aged. Aging. Domestic violence. Whistleblowing.

\section{Referências}

ALVES, Luciana Correia et al. A influência das doenças crônicas na capacidade funcional dos idosos do município de São Paulo, Brasil. Cadernos de Saúde Pública, Rio de Janeiro, v. 23, n. 8, p. 1.924-1.930, 2007. Disponível em: $<$ http://www.scielo.br/scielo.php?script=sci arttext\&pid=S0102-311X2007000800019>. Acesso em: 14 set. 2015.

BRASIL. Presidência da República. Subsecretaria de Direitos Humanos. Plano de Ação para o Enfrentamento da Violência contra a Pessoa Idosa. Brasília: Subsecretaria de Direitos Humanos, 2005.

Estatuto do idoso: Lei federal $\mathrm{n}^{\mathrm{o}} 10.741$, de 01 de outubro de 2003. Brasília, DF: Secretaria Especial dos Direitos Humanos, 2004.

CORREIA, Thyago Moreira Paranhos et al. Perfil dos idosos em situação de violência atendidos em serviço de emergência em Recife-PE. Revista Brasileira de Geriatria e Gerontologia, Rio de Janeiro, v. 15, n. 3, p. 529-536, 2012. Disponível em: <http://www.scielo.br/scielo.php?pid=S1809$-98232012000300013 \&$ script $=$ sci_arttext $>$. Acesso em: 14 set. 2015.

FALEIROS, Vicente de Paula. Violência na velhice. O Social em Questão, Rio de Janeiro, v. 1, n. 1, p. 7-30, 2004. Disponível em: 
$<$ http://osocialemquestao.ser.puc-rio.br/media/v08n11a02.pdf>. Acesso em: 13 set. 2015.

Violência contra a pessoa idosa ocorrências, vítimas e agressores. Brasília: Universa, 2007.

GAIOLI, Cheila Cristina Leonardo de Oliveira; RODRIGUES, Rosalina Aparecida Partezani. Ocorrência de maus-tratos em idosos no domicílio. Revista Latino-Americana de Enfermagem, Ribeirão Preto, v. 16, n. 3, p. 465470, 2008. Disponível em: <http://www.scielo. br/scielo.php?script=sci_arttext\&pid=S0104$-11692008000300021 \& \operatorname{lng}=\mathrm{en} \& \mathrm{nrm}=\mathrm{iso} \& \ln$ $\mathrm{g}=\mathrm{pt}>$. Acesso em: 13 set. 2015 .

GALVÃO, Elaine Ferreira; ANDRADE, Selma Maffei de. Violência contra a mulher: análise de casos atendidos em serviço de atenção à mulher em município do Sul do Brasil. Saúde e Sociedade, São Paulo, v. 13, n. 2, p. 89-99, 2004. Disponível em: $<$ http://www.scielo.br/scielo.php?pid=S0104-12902004000200009 \& script =sci_ abstract\&tlng=pt>. Acesso em: 12 set. 2015.

HAZZARD, William R. et al. Principles of geriatric medicine and gerontology. 5. ed. New York: McGraw Hill, 2003.

MAIA, Rodrigo da Silva; MAIA, Eulália Maria Chaves Maia. Prevalence of violence and related aspects: preliminary study of older adults. Revista de Enfermagem UFPE On Line, v. 9, supl. 7, p. 8.961-8.968, 2015. Disponível em: <http://www.revista.ufpe. br/revistaenfermagem/index.php/revista/ article/view/7081>. Acesso em: 13 set. 2015.

MAIA, Rodrigo da Silva et al. La violencia contra los ancianos: una visión general de as últimas novedades científicas. In: CONGRESSO VIRTUAL DE PSIQUIATRÍA, 11, 2010, Madrid. Anais... Madrid, 2010. Disponível em: <http://www.psiquiatria.com/ bibliopsiquis/handle/10401/960>. Acesso em: 12 set. 2015.

MELO, Victor Lopes de; CUNHA, Juliana de Oliveira Carneiro da; FALBO NETO, Gilliatt Hanois. Maus-tratos contra idosos no muni- cípio de Camaragibe, Pernambuco. Revista Brasileira de Saúde Materno-Infantil, Recife, v. 6, supl. 1, p. s43-s48, 2006. Disponível em: <http://www.scielo.br/scielo.php?script=sci_ arttext\&pid=S1519-38292006000500006\&lng= pt\&nrm=iso\&tlng=pt>. Acesso em: 12 set. 2015.

MAZZA, Márcia Maria Porto Rossetto; LEFEVRE, Fernando. Cuidar em família: análise da representação social da relação do cuidador familiar com o idoso. Revista Brasileira de Crescimento e Desenvolvimento Humano, São Paulo, v. 15, n. 1, p. 1-10, 2005. Disponível em: <http:// pepsic.bvsalud.org/scielo.php?pid=S0104$-12822005000100002 \&$ script=sci_arttext $>$. Acesso em: 12 set. 2015

MINAYO, Maria Cecília de Souza. Violência contra idosos: relevância para um velho problema. Cadernos de Saúde Pública, Rio de Janeiro, v. 19, n. 3, p. 783-791, 2003. Disponível em: <http://www.scielo.br/scielo.php?pid=S0102-311 X2003000300010\&script=sci_arttext $>$. Acesso em: 12 set. 2015.

NERI, Anita Liberalesso. Qualidade de vida e idade madura. Campinas: Papirus, 1993.

OLIVEIRA, Walter Ferreira de. Violência e saúde coletiva: contribuições teóricas das ciências sociais à discussão sobre o desvio. Saúde e Sociedade, São Paulo, v. 17, n. 3, p. 42-53, 2008. Disponível em: <http:// www.scielo.br/scielo.php?script=sci_arttext \&pid=S0104-12902008000300006 >. Acesso em: 12 set. 2015.

ORGANIZAÇÃO MUNDIAL DA SAÚDE. Envelhecimento ativo: uma política de saúde. Brasília: Organização Pan-Americana da Saúde, 2005. Disponível em: <http://bvsms. saude.gov.br/bvs/publicacoes/envelhecimento_ativo.pdf $>$. Acesso em: 12 set. 2015.

Global status report on violence prevention. Genebra: Organização Mundial da Saúde, 2014. Disponível em: <http://www.who. int/violence_injury_prevention/violence/status_report/2014/en/>. Acesso em: 8 jul. 2016.

RBCEH, Passo Fundo, v. 13, n. 2, p. I13-123, maio/ago. 2016 
Relatório mundial sobre violência e saúde. Genebra: Organização Mundial da Saúde, 2002. Disponível em: <http://www. academia.edu/7619294/Relat\%C3\%B3rio_ mundial_sobre_viol\%C3\%AAncia_e_ sa\%C3\%BÄde>. Acesso em: 12 set. 2015.

PLONER, Katia Simone; HOFFMANN, Rosimar Marques; BALDISSERA, Fernanda de Bortoli. Violência contra idosos: análise das denúncias e seu atendimento no CREAS. Revista Brasileira de Ciências do Envelhecimento Humano, Passo Fundo, v. 11, n. 2, p. 141-151, 2014. Disponível em: <http:// www.upf.br/seer/index.php/rbceh/article/ view/4009/pdf>. Acesso em: 20 fev. 2016.

SALES, Diane Sousa et al. A violência contra o idoso na visão do agente comunitário de saúde. Estudos Interdisciplinares sobre o Envelhecimento, Porto Alegre, v. 19, n. 1, p. 63-77, 2014. Disponível em: <http://seer. ufrgs.br/index.php/RevEnvelhecer/article/ view/36910/31001>. Acesso em: 14 set. 2015.

SANCHES, Ana Paula R. Amadio; LEBRÃO, Maria Lúcia; DUARTE, Yeda Aparecida de Oliveira. Violência contra idosos: uma questão nova? Saúde e Sociedade, São Paulo, v. 17, n. 3, p. 90-100, 2008. Disponível em: $<$ http://www.scielo.br/scielo.php?pid=S0104$-12902008000300010 \&$ script=sci_arttext $>$. Acesso em: 12 set. 2015.

SOUZA, Edinilsa Ramos de et al. Rede de proteção aos idosos do Rio de Janeiro: um direito a ser conquistado. Ciência \& Saúde Coletiva, Rio de Janeiro, v. 13, n. 4, p. 1.153-1.163, 2008. Disponível em: <http://www.scielo.br/scielo.php?pid=S1413$-81232008000400011 \&$ script $=$ sci $_{-}$ abstract\&tlng=pt>. Acesso em: 12 set. 2015.

VERAS, Renato. Envelhecimento populacional contemporâneo: demandas, desafios e inovações. Revista de Saúde Pública, São Paulo, v. 43, n. 3, p. 548-554, 2009. Disponível em: $<$ http://www.scielo.br/scielo.php?pid=S0034$-89102009005000025 \&$ script $=$ sci_arttext $>$. Acesso em: 12 set. 2015. 